\title{
Upper and Lower Limb Muscles in Patients With COPD: Similarities in Muscle Efficiency But Differences in Fatigue Resistance
}

\author{
Eduardo Foschini Miranda PT PhD, Carla Malaguti PT PhD, \\ Paulo Henrique Marchetti PhD, and Simone Dal Corso PT PhD
}

\begin{abstract}
BACKGROUND: Peripheral muscle dysfunction is a common finding in patients with COPD; however, the structural adaptation and functional impairment of the upper and lower limb muscles do not seem to be homogenous. We compared muscle fatigue and recovery time between 2 representative muscles: the middle deltoid and the quadriceps femoris. METHODS: Twenty-one subjects with $C O P D\left(F^{2} V_{1} 46.1 \pm 10.3 \%\right.$ of predicted $)$ underwent maximal voluntary isometric contraction and an endurance test $(60 \%$ of maximal voluntary isometric contraction, to the limit of tolerance). The maximal voluntary isometric contraction test was repeated after $10 \mathrm{~min}, 30 \mathrm{~min}, 60 \mathrm{~min}$, and 24 hours for both the quadriceps femoris and middle deltoid. Surface electromyography was recorded throughout the endurance test. RESULTS: Maximal voluntary isometric contraction significantly decreased only for the middle deltoid between 10 and $60 \mathrm{~min}$ after the endurance test. A significant increase of the root mean square and a greater decline in median frequency throughout the endurance test occurred for the middle deltoid, compared with the quadriceps femoris. When dyspnea and fatigue scores were corrected by endurance time, higher values were observed for the middle deltoid $(0.07$ and 0.08 , respectively) in relation to the quadriceps femoris $(0.02$ and 0.03, respectively). CONCLUSIONS: Subjects with COPD had a higher fatigability of a representative upper limb muscle (middle deltoid) than a lower limb muscle (quadriceps femoris). Key words: COPD; muscle fatigue; electromyography; upper limbs; lower limbs. [Respir Care 2014;59(1): 62-69. (C) 2014 Daedalus Enterprises]
\end{abstract}

\section{Introduction}

It is well established that patients with COPD have impaired skeletal muscle function, which plays a role in re-

Dr Miranda and Dr Dal Corso are affiliated with the Postgraduate Program in Rehabilitation Sciences, Nove de Julho University, São Paulo, Brazil. Dr Malaguti is with the Physiology Department, Universidade Federal de Juiz de Fora, Juiz de Fora, Brazil. Dr Marchetti is affiliated with the Postgraduate Program in Human Performance, Methodist University of Piracicaba, São Paulo, Brazil.

Mr Miranda was partly supported by a master scholarship from Fundação de Amparo à Pesquisa do Estado de São Paulo, São Paulo, Brazil.

The authors have disclosed no conflicts of interest.

Correspondence: Simone Dal Corso PT PhD, Postgraduate Program in Rehabilitation Sciences, Universidade Nove de Julho, Rua Vergueiro 235/249, Bairro Liberdade, São Paulo 01504-001, Brazil. E-mail: foschinimedu@hotmail.com.

DOI: $10.4187 /$ respcare.02439 ducing exercise tolerance. ${ }^{1}$ Although the impairment of lower limb muscles is largely responsible for limitations in activities such as walking and climbing stairs, it is known that activities of daily living (ADLs) performed with upper limbs, especially unsupported, are also poorly tolerated by patients with COPD. ${ }^{2}$

Although reduced skeletal muscle function has been reported in both the lower limbs and the shoulder girdle muscles of patients with COPD, it has been speculated that the metabolic and structural adaptations differ between the lower limb and upper limb muscles. ${ }^{3}$ For the lower limbs the quadriceps femoris is the peripheral muscle most commonly tested in COPD. ${ }^{4}$ Abnormalities of this muscle include $^{1}$ : reduced muscle mass, strength, endurance, oxidative enzymes, and proportion of type I fibers; augmentation of the proportion of type II fibers; and decreased crosssectional area of types I, IIa, and IIab fibers. These changes increase the fatigability of the quadriceps femoris, which has been demonstrated in both dynamic ${ }^{5,6}$ and isometric contractions. ${ }^{7}$ 
For the upper limbs a variety of muscles have been studied, making it difficult to generalize upper limb performance results. ${ }^{2,8}$ Because of the finding that the isometric handgrip force is conserved in patients with COPD, some studies infer that the upper limb function is preserved. ${ }^{9-11}$ It appears that oxidative capacity is preserved or even increased in the deltoid muscles of patients with COPD, ${ }^{9}$ as opposed to what is observed in lower limb muscles. One possible explanations for this difference is that patients continue to perform, to a certain extent, the ADLs that involve the upper limbs, but reduce their performance of the activities that involve the lower limbs, adopting a sedentary lifestyle in order to minimize dyspnea. That finding was prevalent in patients with severe COPD. However, patients have higher metabolic and ventilatory demand when performing activities involving unsupported arm elevation, with important dyspnea. ${ }^{12-14}$ The middle deltoid is directly involved in all ADLs with upper limbs, especially those that require elevation of shoulders. Unlike the quadriceps femoris, it seems that the middle deltoid has a multi-mode fiber distribution (ie, normal, atrophic, and hypertrophic sizes ${ }^{15}$ ), which could influence the development of muscle fatigue when performing ADLs with upper limbs.

Few studies have compared lower limb and upper limb muscle function..$^{4,16-19}$ Some studies support a greater impairment of lower limb muscles ${ }^{10,17,19}$ than upper limb muscles, because these patients reduce the physical activities that use the lower limbs, ${ }^{20}$ thus preserving upper limb activities. On the other hand, studies have shown that the muscle impairment is similar in the upper and lower limbs muscles, ${ }^{18}$ with comparable mechanical efficiency. ${ }^{17}$

Due to ongoing controversy about the muscle impairment distribution between lower limb and upper limb, this study was undertaken to contrast the muscle fatigue between 2 representative muscles, the quadriceps femoris and the middle deltoid, by analyzing electromyographic changes at equivalent work loads, and their recovery times after muscle fatigue.

\section{Methods}

This study was approved by the Universidade Nove de Julho institutional ethics committee. Informed consent was obtained from all subjects prior to inclusion.

We studied 21 consecutive patients from the out-patient clinic at Nove de Julho University. The inclusion criteria were clinical diagnosis of COPD and clinical stability (no change in medication dosage in the preceding 4 weeks or during the study). The exclusion criteria were cardiac, orthopedic, and neurological diseases.

\section{QUICK LOOK}

\section{Current knowledge}

Impaired skeletal muscle function is common and reduces exercise tolerance in patients with COPD. Lower-limb muscle impairment is largely responsible for limitations in activities of daily living.

\section{What this paper contributes to our knowledge}

COPD patients had higher fatigability of a representative upper-limb muscle, compared with a lower-limb muscle.

\section{Study Design}

This was a prospective, cross-sectional study performed in 2 visits, $24 \mathrm{~h}$ apart. The subjects were assessed at the same time of day (between 2:00 and 3:00 pm), and they were instructed to refrain from any strenuous activities in the $72 \mathrm{~h}$ before the procedure. The order of muscle evaluation (quadriceps femoris, then middle deltoid; or middle deltoid, then quadriceps femoris) was randomized. On the first visit the subjects underwent the following sequence of tests: maximum voluntary isometric contraction (MVIC), isometric endurance test ( $60 \%$ of MVIC) to the limit of tolerance, and repetition of MVIC after $10 \mathrm{~min}, 30 \mathrm{~min}$, $60 \mathrm{~min}$, and 24 hours later. Then, the other muscle was evaluated in the same sequence. At the second visit the subjects underwent MVIC of the quadriceps femoris and middle deltoid, to compare the recovery time after muscle fatigue. All measurements were made with electromyography. There was a rest period of $5 \mathrm{~min}$ between sequences 1 and 2.

\section{Spirometry}

Spirometry (CPFS/D USB, Medical Graphics, St Paul, Minnesota) was per the American Thoracic Society/ European Respiratory Society criteria, ${ }^{21}$ and FVC, FEV ${ }_{1}$, and $\mathrm{FEV}_{1} / \mathrm{FVC}$ are expressed in absolute values and percent of predicted. ${ }^{22}$

\section{Skeletal Muscle Function Assessment}

The strength of the quadriceps femoris was obtained on the dominant leg, via MVIC, with the subject seated on a leg extension chair (Carci, São Paulo, Brazil), at $60^{\circ}$ knee flexion. A non-elastic strap connected the ankle to a load cell (EMG800C, EMG Systems, São José dos Campos, Brazil), which was interfaced to a computer for MVIC recording. A strap was also placed across the subject's 
pelvis to minimize hip movement during the test. Each subject performed 3 repetitions of MVIC of the knee extensors, each one maintained for $5 \mathrm{~s}$, with a minute of rest between them. The highest value from the 3 reproducible contractions ( $<5 \%$ variability among attempts) was analyzed. ${ }^{23}$

After a rest period of 5 min the endurance of the quadriceps femoris was evaluated with the isometric endurance test, at $60 \%$ of the MVIC, to the limit of tolerance. ${ }^{23} \mathrm{~A}$ visual reference mark corresponding to the submaximal work load was shown on a computer screen in front of the subject for visual feedback. In addition, during the whole test, verbal encouragement was given for the subject to maintain contraction as long as possible. The isometric endurance test stopped when a $20 \%$ drop of the produced force occurred.

The MVIC of the middle deltoid of the dominant arm was measured with the subject seated on a chair. The shoulder was placed at $90^{\circ}$ abduction, with the elbow extended and the palm of the hand facing up. This level of shoulder elevation was chosen because it is a common position for several ADLs performed with the upper limb. A load cell was attached with a strap to the wrist of the subject's dominant arm. Following the same sequence used in the quadriceps femoris assessment, the subject first performed 3 brief (5-s) reproducible MVICs of the middle deltoid, with a minute of rest between them. The highest value was analyzed. Then the subject sustained a submaximal isometric contraction against $60 \%$ of the MVIC, to the limit of tolerance. Visual feedback was provided on the computer screen during all measurements.

Scores for dyspnea and leg (quadriceps femoris) and arm (middle deltoid) fatigue, before and after endurance tests, were assessed with the modified Borg scale. ${ }^{24}$ Dyspnea and fatigue scores were corrected for endurance time in order to adjust the perception of effort for work performed by each muscle.

\section{Surface Electromyography}

Surface electromyography (sEMG) signals were recorded with the EMG800C during the MVIC, submaximal isometric contraction, and endurance tests. The sEMG signals were also recorded with a preamplifier (gain 1,000×), with common mode rejection $>-85 \mathrm{~dB}$. Before placement of the EMG electrodes the subject's skin was prepared by shaving the hair at the site of electrode placement and cleaning the skin with alcohol. Bipolar passive disposable dual $\mathrm{Ag} / \mathrm{AgCl}$ snap electrodes ( $1 \mathrm{~cm}$ diameter) for each circular conductive area, with $2 \mathrm{~cm}$ center-to-center spacing, were placed over the longitudinal axes of the quadriceps femoris and middle deltoid, in the direction of the muscle fiber, according to the Surface Electromyography for the Noninvasive Assessment of Muscles
(SENIAM)/Iseki protocol. ${ }^{25} \mathrm{~A}$ ground electrode was placed on the contralateral elbow. The sampling frequency was $1,000 \mathrm{~Hz} .{ }^{26}$ The criterion adopted to normalize the sEMG data were the MVIC. Then the digitized sEMG data were band-pass filtered at $20-400 \mathrm{~Hz}$, using a fourth-order Butterworth filter with zero lag. For the temporal analysis the amplitude of the sEMG signals was expressed as the root mean square (1-s moving window) and normalized by MVIC. For the time-frequency analysis, sEMG data were analyzed with a short-time Fourier transform applied to 1-s epochs. The median frequency of the spectrum for each epoch was computed, and the linear regression of the median frequencies versus time was determined. The slope of the straight line (indicating the rate of frequency change per second) was adopted as a second index of fatigue. ${ }^{27-29}$ All data were analyzed using a customized program written in Matlab (MathWorks, Natick, Massachusetts). The MVIC was corrected by muscle mass.

\section{Body Mass Index}

Body mass index was calculated as weight/height ${ }^{2}$ $\left(\mathrm{kg} / \mathrm{m}^{2}\right)$. Body weight was assessed with a beam scale to the nearest $0.1 \mathrm{~kg}$, with the subject standing barefoot and in light clothing. Body height was determined to the nearest $0.1 \mathrm{~cm}$, with the subject standing barefoot.

\section{Mid-Arm Muscle Area}

The mid-arm muscle area was estimated ${ }^{30}$ using the following equation:

Mid-arm muscle area $=$

mid-arm circumference, $\mathrm{cm}-(0.314 \times \text { triceps skinfold, } \mathrm{cm})^{2} /(4 \times 3.14)$

The mid-arm circumference was measured at the midpoint of the arm, between the tip of the acromion and the olecranon process, with a steel tape with the arm relaxed and parallel to the trunk. A skinfold caliper (Lange, Beta Technology, Cambridge, Maryland) was used to measure the triceps skinfold, which was taken over the triceps muscle, halfway between the elbow and acromial process of the scapula. ${ }^{31}$ Triceps skinfold is expressed in $\mathrm{cm}^{2}$.

\section{Mid-Thigh Muscle Area}

To estimate the mid-thigh muscle area, mid-thigh circumference and anterior thigh skinfold were taken midway between the inguinal crease and the top of the patella, with the subject standing with feet shoulder-width apart. The same steel tape and skinfold caliper were used as for the mid-arm muscle area. The mid-thigh muscle area was calculated $^{32}$ as: 
Table 1. Baseline Characteristics of Subjects

\begin{tabular}{lc}
\hline \hline & Mean $\pm \mathrm{SD}$ \\
\hline Age, years & $70 \pm 10.2$ \\
Body mass index, $\mathrm{kg} / \mathrm{m}^{2}$ & $25.5 \pm 5.2$ \\
Arm muscle area, $\mathrm{cm}^{2}$ & $49.7 \pm 18.9$ \\
Thigh muscle area, $\mathrm{cm}^{2}$ & $128.8 \pm 32.6$ \\
$\mathrm{FVC}, \mathrm{L}(\%$ predicted $)$ & $2.2 \pm 0.8(68.2 \pm 16.8)$ \\
$\mathrm{FEV}_{1}, \mathrm{~L}(\%$ predicted $)$ & $1.1 \pm 0.3(46.1 \pm 10.3)$ \\
$\mathrm{FEV}_{1} / \mathrm{FVC}, \%$ & $58.7 \pm 12.9$ \\
\hline
\end{tabular}

Mid-thigh muscle area $=$

mid-thigh, $\mathrm{cm}-(0.314 \times \text { anterior thigh skinfold, } \mathrm{cm})^{2} /(4 \times 3.14)$

Mid-thigh muscle area is expressed in $\mathrm{cm}^{2}$.

\section{Statistical Analysis}

Based on the results from the 5 first subjects, we obtained a standard deviation for median frequency of $8 \mathrm{~Hz}$, and a difference of $7 \mathrm{~Hz}$ between the pre- and post-endurance test. Assuming a type I error of 0.05 and a type II error of 0.2 , we calculated a needed sample size of 21 subjects with COPD. The normal distribution of data were verified with the Kolmogorov-Smirnov test. Age, body mass index, middle deltoid muscle area, quadriceps femoris muscle area, lung function, and Borg scores for dyspnea and fatigue are expressed as mean $\pm \mathrm{SD}$, by presenting a parametric distribution. Changes in MVIC, root mean square, and median frequency over time were analyzed via repeated-measures analysis of variance. Linear regression analysis over time was applied to the rate of change of median frequency, to obtain the slope of the regression line. The level of significance was set at $P<.05$.

\section{Results}

Baseline characteristics of the 21 subjects (2 women) are shown in Table 1. According to the GOLD criteria, most of the subjects $(n=15)$ had severe obstruction, and the 6 remaining subjects had moderate obstruction.

Table 2 shows the results from the strength and endurance tests. The middle deltoid showed lower MVIC than the quadriceps femoris $(P=.001)$. No significant difference was observed when MVIC was corrected for muscle mass, but we found significant difference in the limit of tolerance in the endurance test corrected for the MVIC $(P=.005)$. The submaximal work load performed by the middle deltoid was lower than that of quadriceps femoris. Although the same MVIC percentage $(60 \%)$ for the endurance test was used for both muscles, the endurance time for the middle deltoid was about $40 \%$ of that of quadriceps femoris (Fig. 1).
Table 2. Muscle Strength and Endurance Results

\begin{tabular}{lcr}
\hline \hline & $\begin{array}{c}\text { Middle } \\
\text { Deltoid }\end{array}$ & $\begin{array}{c}\text { Quadriceps } \\
\text { Femoris }\end{array}$ \\
\hline MVIC, kg & $6.7 \pm 2.5$ & $16.0 \pm 5.2 *$ \\
MVIC/muscle mass & $0.15 \pm 0.05$ & $0.13 \pm 0.05$ \\
Load of endurance test, $\mathrm{kg}$ & $4.0 \pm 1.6$ & $9.8 \pm 3.1^{*}$ \\
Limit of tolerance, $\mathrm{s}$ & $49.6 \pm 39.2$ & $127.1 \pm 76.5^{*}$ \\
Limit of tolerance/load & $13 \pm 9$ & $15 \pm 12^{*}$ \\
$\quad$ endurance test, s/kg $\dagger$ & & \\
\hline $\begin{array}{l}\text { Values are mean } \pm \mathrm{SD} \\
*<.05 .\end{array}$ & \\
$\dagger$ Limit of tolerance of the endurance test, corrected for the maximal voluntary isometric \\
contraction (MVIC). \\
\end{tabular}

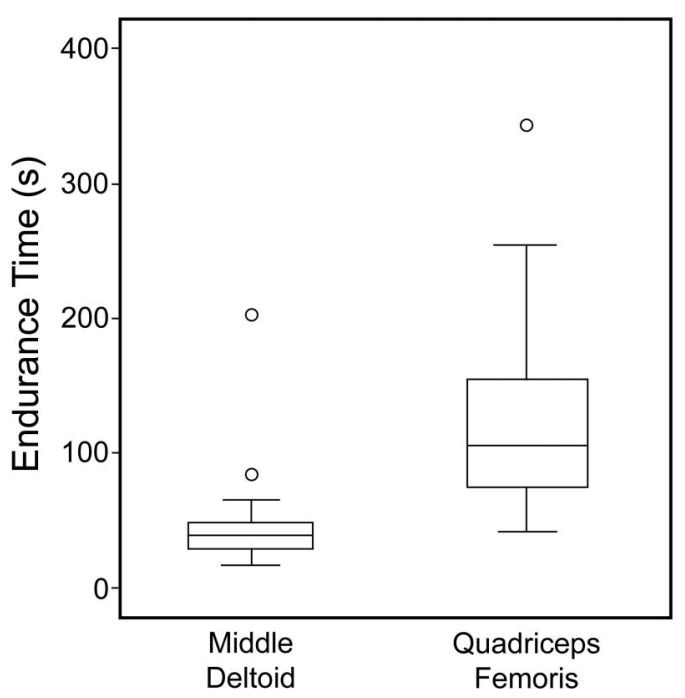

Fig. 1. Endurance time for the middle deltoid and quadriceps femoris muscles. In each data bar the horizontal line represents the median, the top and bottom of the bar represent the interquartile range, the whisker bars represent the 5th and 95th percentiles, and the circles represent outliers.

There was a significant drop in MVIC in the middle deltoid at 10 and $60 \mathrm{~min}$, but not at $30 \mathrm{~min}$ and $24 \mathrm{~h}$ after the endurance test (Fig. 2).

Figure $3 \mathrm{~A}$ shows a significant increase in the root mean square of the middle deltoid, compared to the quadriceps femoris, only in $25 \%$ of the endurance test (percent duration). Figure 3B shows a greater decline in median frequency throughout the endurance test for the middle deltoid, compared to the quadriceps femoris.

There was a significant difference in the slope of the median frequency over time between the middle deltoid and the quadriceps femoris $(-3.77 \pm 1.4$ and $-2.68 \pm 1.2$, respectively, $P=.004$ ).

In relation to perceived exertion, the majority of the subjects stopped the endurance test due to local muscle fatigue (middle deltoid 18 subjects, quadriceps femoris 16 


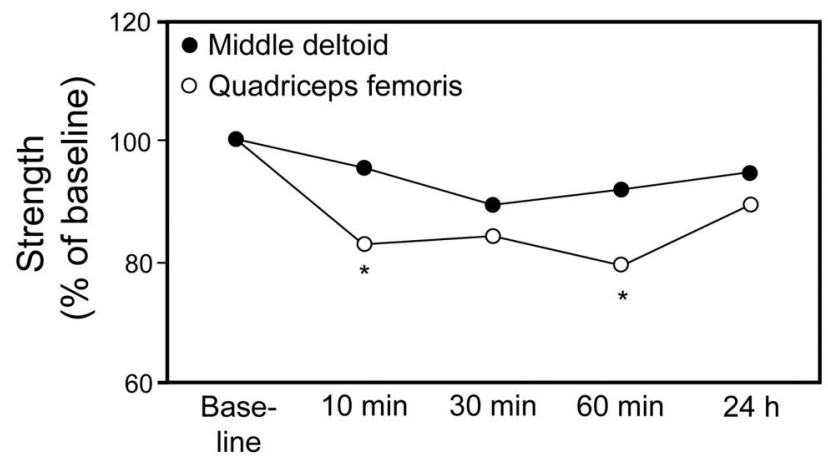

Fig. 2. Changes in maximum voluntary isometric contraction (strength) in the quadriceps femoris and middle deltoid muscles. ${ }^{*} P<.05$ compared to baseline for middle deltoid.
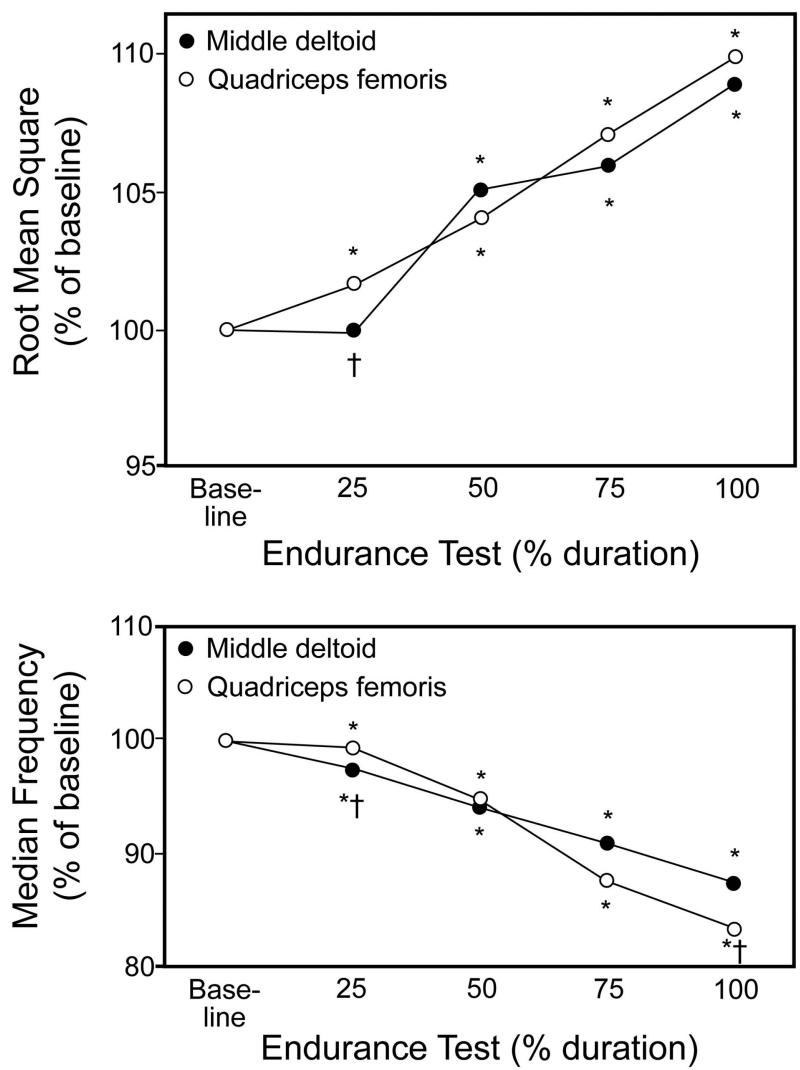

Fig. 3. Changes in the root mean square and median frequency for the quadriceps femoris and middle deltoid muscles. ${ }^{*} P<.05$ compared to baseline and among exercise time (percent duration) for both muscles. $† P<.05$ for quadriceps femoris versus middle deltoid.

subjects). Three subjects had higher dyspnea scores for the middle deltoid, and 5 subjects for the quadriceps femoris. The ratings of perceived exertion for dyspnea and fatigue were significantly higher for the quadriceps femoris (from $1.3 \pm 0.8$ to $2.1 \pm 1.2$, and $1.3 \pm 1.0$ to $2.8 \pm 1.3$, respectively) and the middle deltoid (from $1.4 \pm 0.9$ to $2.7 \pm 1.9$, and $1.6 \pm 1.1$ to $3.2 \pm 1.7$, respectively). When corrected for endurance time, the dyspnea and fatigue scores were higher for the middle deltoid $(0.07$ and 0.08 , respectively) than for the quadriceps femoris (0.02 and 0.03, respectively) $(P=.009)$.

\section{Discussion}

Our main finding is that, despite similar muscle efficiency, muscle fatigue was evident earlier and was more pronounced in the middle deltoid. The lower muscle strength of the middle deltoid, compared to the quadriceps femoris, was expected. Similar results have been shown for the biceps brachii in relation to the quadriceps femoris. ${ }^{18}$ Although Gosker et $\mathrm{al}^{18}$ have measured the fat free mass, muscle strength has not been corrected for muscle mass, which reflects the efficiency of muscle. In our study the muscle-strength difference between the middle deltoid and the quadriceps femoris disappeared after correcting for muscle mass, so muscle efficiency was similar between the middle deltoid and the quadriceps femoris, indicating that the contractile apparatus was preserved. ${ }^{19}$ Therefore, the difference in endurance time between the middle deltoid and the quadriceps femoris suggests that neither strength nor muscle mass is a determinant of muscle endurance.

The reduction of muscle endurance, regardless of loss of muscle mass, in patients with COPD has been related to intrinsic muscle alterations such as reduction of type I fibers and reduced oxidative enzyme activity. ${ }^{1}$ Consequently, there is a predominance of anaerobic metabolism, resulting in early lactate accumulation and muscle fatigue. In absolute values, the dyspnea and fatigue scores were similar at the peak of both endurance tests. However, the endurance time was lower for the middle deltoid (see Table 2). When corrected for the endurance time (ie, work performed), dyspnea and fatigue were higher for the middle deltoid. Local muscle fatigue might be due to increased lactate production per unit of muscle mass. A possible cause of dyspnea is the change in lung volumes (decreased FVC and inspiratory capacity, and increased functional residual capacity) during upper-limb activities. ${ }^{12,33}$ Also, reduction of blood flow during elevation of the upper limbs increases the production of lactate, which increases ventilation demand and, consequently, dyspnea. ${ }^{34,35}$

One of the most common measures of muscle fatigue is the decline in maximum strength. ${ }^{36} \mathrm{We}$ found a greater drop in strength in the middle deltoid than in the quadriceps femoris (see Fig. 1), as did Gosker et al ${ }^{18}$; however, the magnitude of that drop was less in our study, in both muscles: middle deltoid $20.6 \%$, quadriceps femoris $10.6 \%$, versus biceps brachii $42 \%$, quadriceps femoris $28 \%$ in Gosker et al. ${ }^{18}$ The larger decline in strength in the study by Gosker et al ${ }^{18}$ might be attributable to 
their more intense fatigue-inducing protocol (15 sequential maximal voluntary contractions at an angular velocity of $90^{\circ} \mathrm{s}$ ), worse disease severity in their subjects $\left(\mathrm{FEV}_{1} 32 \pm 11 \%\right.$ vs $\left.46 \pm 10 \%\right)$, and lower fat-free mass and strength in the patients than in the control subjects.

Several studies have evaluated quadriceps femoris fatigability after cycling, walking, repeated maximum voluntary contractions, and local endurance tests. ${ }^{37-39}$ However, to the best of our knowledge, only our study has analyzed the recovery time from fatigue after an upper-limb fatigueinducing protocol. In addition to the greater decrease in strength, compared to the quadriceps femoris, the middle deltoid had longer recovery time of the baseline MVIC. Beyond smaller muscle mass, this finding may be explained by the dual function of the accessory respiratory muscles during unsupported arm exercise, ventilation, and postural maintenance, which can contribute to fatigue. ${ }^{15}$ Unlike those observed in the lower limb muscles, alterations in fiber-type distribution and decreased metabolic capacity do not seem to be involved in early fatigue of the upper limb muscles. This assertion is based on previous studies that demonstrated preserved or even increased oxidative capacity, ${ }^{7}$ as well as a concomitant presence of the normal, atrophic, and hypertrophic pattern of fibers within the middle deltoid, when compared to a control group. ${ }^{15}$

Although widely used for evaluation of muscle fatigue, submaximal sustained isometric contraction ${ }^{40-44}$ has the disadvantage of being dependent on motivation. However, we used electromyography during the tests, which provides a more objective evaluation of muscle fatigue. A $4 \%$ decrease in median frequency has been recommended as an indirect marker of contractile fatigue measured via sEMG. ${ }^{45}$ Therefore, while our subjects certainly had muscle fatigue for both the quadriceps femoris and the middle deltoid, it was more pronounced in the middle deltoid, as seen in the higher slope in the median frequency over time (see Fig. 2B). These data cannot be directly compared with other studies in patients with COPD, because no other studies have analyzed it. Compared with healthy subjects, ${ }^{46}$ our COPD subjects had a more pronounced drop in the slope of the median frequency $(-0.67 \mathrm{vs}-3.77$, respectively). Even in healthy subjects ( $61 \pm 6$ y old) performing ADLs with unsupported arm elevation, Panka et $\mathrm{al}^{47}$ found changes in breathing pattern and greater activation of the sternocleidomastoid.

\section{Limitations}

Muscle fatigue was evaluated by volitional measurements (MVIC and endurance time); however, we used sEMG to confirm the muscle fatigue. Our results cannot be extrapolated to other body positions, such as standing po- sition. The lower and upper limb muscle mass were estimated, but the measurements we used have traditionally been used in the literature. ${ }^{30,48} \mathrm{~A}$ huge variability was observed for limit of tolerance for the middle deltoid. Our subjects did not undergo muscle biopsy, but a previous study identified 3 patterns of deltoid muscle composition in subjects with $\mathrm{COPD}^{15}$ : normal size fibers, atrophic fibers, and hypertrophic fibers. Therefore we speculate that the subjects with higher endurance time probably had a predominance of normal size fibers and/or hypertrophic fibers, while those with lower endurance time probably have more atrophic fibers.

Currently, resistance training is a component of pulmonary rehabilitation for patients with COPD. Based on our findings, we suggest that upper-limb training should be accomplished with high-repetition/low-resistance exercises, to increase muscle endurance. Further studies measuring pulmonary gas exchange during a fatigue-inducing protocol will determine whether EMG changes reflect higher oxygen consumption, carbon dioxide production, and/or ventilation. In addition, studies evaluating lung volume, especially inspiratory capacity, could help to explain the increased perception of dyspnea in the upper-limb endurance tests.

\section{Conclusions}

In subjects with COPD the middle deltoid had higher fatigability and longer recovery time than the quadriceps femoris.

\section{REFERENCES}

1. American Thoracic Society and European Respiratory Society. Skeletal muscle dysfunction in chronic obstructive pulmonary disease. Am J Respir Crit Care Med 1999;159(4 Pt 2):S1-S40.

2. Dolmage TE, Maestro L, Avendano MA, Goldstein RS. The ventilatory response to arm elevation of patients with chronic obstructive pulmonary disease. Chest 1993;104(4):1097-1100.

3. Gea J, Orozco-Levi M, Barreiro E, Ferrer A, Broquetas J. Structural and functional changes in the skeletal muscles of COPD patients: the "compartments" theory. Monaldi Arch Chest Dis 2001;56(3): 214-224.

4. Miranda EF, Malaguti C, Corso SD. Peripheral muscle dysfunction in COPD: lower limbs versus upper limbs. J Bras Pneumol 2011; 37(3):380-388.

5. Mador MJ, Bozkanat E, Kufel TJ. Quadriceps fatigue after cycle exercise in patients with COPD compared with healthy control subjects. Chest 2003;123(4):1104-1111.

6. Saey D, Debigarè R, LeBlanc P, Mador MJ, Cote CH, Jobin J, Maltais F. Contractile leg fatigue after cycle exercise. A factor limiting exercise in patients with chronic obstructive pulmonary disease. Am J Respir Crit Care Med 2003;168(4):425-430.

7. Mador MJ, Deniz O, Aggarwal A, Kufel TJ. Quadriceps fatigability after single muscle exercise in patients with chronic obstructive pulmonary disease. Am J Respir Crit Care Med 2003;168(1): 102-108. 


\section{UpPer ANd Lower Limb Muscles in Patients With COPD}

8. Subin, Rao V, Prem V, Sahoo. Effect of upper limb, lower limb and combined training on health-related quality of life in COPD. Lung India 2010;27(1):4-7.

9. Gea JG, Pasto M, Carmona MA, Orozco-Levi M, Palomeque J, Broquetas J. Metabolic characteristics of the deltoid muscle in patients with chronic obstructive pulmonary disease. Eur Respir J 2001; 17(5):939-945.

10. Gosselink R, Troosters T, Decramer M. Peripheral muscle weakness contributes to exercise limitation in COPD. Am J Respir Crit Care Med 1996;153(3):976-980.

11. Degens H, Sanchez Horneros JM, Heijdra YF, Dekhuijzen PN, Hopman MT. Skeletal muscle contractility is preserved in COPD patients with normal fat-free mass. Acta Physiol Scand 2005; 184(3):235-242.

12. Porto EF, Castro AA, Velloso M, Nascimento O, Dal Maso F, Jardim JR. Exercises using the upper limbs hyperinflate COPD patients more than exercises using the lower limbs at the same metabolic demand. Monaldi Arch Chest Dis 2009;71(1):21-26.

13. Colucci M, Cortopassi F, Porto E, Castro A, Colucci E, Iamonti VC, Souza G, Nascimento O, Jardim JR. Upper limb exercises using varied workloads and their association with dynamic hyperinflation in patients with COPD. Chest 2010;138(1):39-46.

14. Velloso M, Stella SG, Cendon S, Silva AC, Jardim JR. Metabolic and ventilatory parameters of four activities of daily living accomplished with arms in COPD patients. Chest 2003;123(4):10471053.

15. Hernández N, Orozco-Levi M, Belalcázar V, Pastó M, Minguella J, Broquetas JM, Gea J. Dual morphometrical changes of the deltoid muscle in patients with COPD. Respir Physiol Neurobiol 2003; 134(3):219-229

16. Franssen FM, Wouters EF, Baarends EM, Akkermans MA, Schols AM. Arm mechanical efficiency and arm exercise capacity are relatively preserved in chronic obstructive pulmonary disease. Med Sci Sports Exerc 2002;34(10):1570-1576.

17. Castagna O, Boussuges A, Vallier JM, Prefaut C, Brisswalter J. Is impairment similar between arm and leg cranking exercise in COPD patients? Respir Med 2007;101(3):547-553.

18. Gosker HR, Lencer NH, Franssen FM, van der Vusse GJ, Wouters EF, Schols AM. Striking similarities in systemic factors contributing to decreased exercise capacity in patients with severe chronic heart failure or COPD. Chest 2003;123(5):1416-1424.

19. Bernard S, LeBlanc P, Whittom F, Carrier G, Jobin J, Belleau R, Maltais F. Peripheral muscle weakness in patients with chronic obstructive pulmonary disease. Am J Respir Crit Care Med 1998;158(2): 629-634.

20. Pitta F, Troosters T, Spruit MA, Probst VS, Decramer M, Gosselink R. Characteristics of physical activities in daily life in chronic obstructive pulmonary disease. Am J Respir Crit Care Med 2005;171(9): 972-977.

21. Pellegrino R, Viegi G, Brusasco V, Crapo RO, Burgos F, Casaburi $\mathrm{R}$, et al. Interpretative strategies for lung function tests. Eur Respir $\mathrm{J}$ 2005;26(5):948-968.

22. Pereira CAC, Barreto SP, Simões JG. Valores de referência para espirometria em uma amostra da população brasileira adulta. J Pneumol 1992;18:10-22. Article in Portuguese.

23. Mathur S, Eng JJ, MacIntyre DL. Reliability of surface EMG during sustained contractions of the quadriceps. J Electromyogr Kinesiol 2005; 15(1):102-110.

24. Borg G. Psychophysical scaling with applications in physical work and the perception of exertion. Scand J Work Environ Health 1990; 16(Suppl 1):55-58

25. Hermens HJ, Freriks B. Development of recommendations for SEMG sensors and sensor placement procedures. J eletromyogr Kinesiol 2000;10(5):361-374.
26. Alkner BA, Tesch PA, Berg HE. Quadriceps EMG/force relationship in knee extension and leg press. Med Sci Sports Exerc 2000;32(2): 459-463.

27. Madeleine P, Farina D, Merletti R, Arendt-Nielsen L. Upper trapezius muscle mechanomyographic and electromyographic activity in humans during low force fatiguing and non-fatiguing contractions. Eur J Appl Physiol 2002;87(4-5):327-336.

28. Merletti R, Lo Conte L, Cisari C, Actis MV. Age related changes in surface myoelectric signals. Scand J Rehabil Med 1992;24(1):25-36.

29. Merletti R, Farina D, Gazzoni M, Schieroni MP. Effect of age on muscle functions investigated with surface electromyography. Muscle Nerve 2002;25(1):65-76.

30. Soler Cataluna JJ, Sánchez Sánchez L, Martinez Garcia MA, Román Sanchez P, Salcedo E, Navarro M. Mid-arm muscle area is a better predictor of mortality than body mass index in COPD. Chest 2005; 128(4):2108-2115.

31. Frisancho AR. New norms of upper limb fat and muscle areas for assessment of nutritional status. Am J Clin Nutr 1981;34(11): 2540-2545.

32. Jones PR, Pearson J. Anthropometric determination of leg fat and muscle plus bone volumes in young male and female adults. J Physiol 1969;204(2):63P-66P.

33. Martinez FJ, Couser JI Jr, Celli BR. Respiratory response to arm elevation in patients with chronic obstructive pulmonary disease. Am Rev Respir Dis 1991;143(3):476-480.

34. Lind AR, Taylor SH, Humphreys PW, Kennelly BM, Donald KW. The circulatory effects of sustained voluntary muscle contraction. Clin Sci 1964;27:229-244.

35. Bevegard S, Freyschuss U, Strandell T. Circulatory adaptation to arm and leg exercise in supine sitting position. J Appl Physiol 1966; 21(1):37-46.

36. Man WD, Soliman MG, Nikoletou D, Harris ML, Rafferty GF, Mustfa N, et al. Non-volitional assessment of skeletal muscle strength in patients with chronic obstructive pulmonary disease. Thorax 2003; 58(8):665-669.

37. Man WD, Soliman MG, Gearing J, Radford SG, Rafferty GF, Gray BJ, et al. Symptoms and quadriceps fatigability after walking and cycling in chronic obstructive pulmonary disease. Am J Respir Crit Care Med 2003;168(5):562-567.

38. Mador MJ, Kufel TJ, Pineda LA, Steinwald A, Aggarwal A, Upadhyay AM, Khan MA. Effect of pulmonary rehabilitation on quadriceps fatiguability during exercise. Am J Respir Crit Care Med 2001;163(4):930-935.

39. Coronell C, Orozco-Levi M, Méndez R, Ramírez-Sarmiento A, Gáldiz JB, Gea J. Relevance of assessing quadriceps endurance in patients with COPD. Eur Respir J 2004;24(1):129-136.

40. Princivero DM, Coelho AJ. Activation linearity and parallelism of the superficial quadriceps across the isometric intensity spectrum. Muscle Nerve 2000;23(3):393-398.

41. Rainoldi A, Bullock-Saxton JE, Cavarretta F, Hogan N. Repeatability of maximal voluntary force and of surface EMG variables during voluntary isometric contraction of quadriceps muscles in healthy subjects J Electromyogr Kinesiol 2001;11(6):425-438.

42. Kollmitzer J, Ebenbichler GR, Kopf A. Reability of surface electromyographic measurements. Clin Neurophysiol 1999;110(4): 725-734.

43. Gayda M, Merzouk A, Choquet D, Ahmaidi S. Assessment of skeletal muscle fatigue in men with coronary artery disease using surface electromyography during isometric contraction of quadriceps muscles. Arch Phys Med Rehabil 2005;86(2):210-215.

44. Ludewig PM, Cook TM, Nawoczenski DA. Three-dimensional scapular orientation and muscle activity at selected positions of humeral elevation. J Orthop Sports Phys Ther 1996;24(2):57-65. 


\section{Upper and Lower Limb Muscles in Patients With COPD}

45. Saey D, Côté CH, Mador MJ, Laviolette L, Lesblanc P, Jobin J, Maltais F. Assessment of muscle fatigue during exercise in chronic obstructive pulmonary disease. Muscle Nerve 2006;34(1): 62-71.

46. Minning S, Eliot CA, Uhl TL, Malone TR. EMG analysis of shoulder muscle fatigue during resisted isometric shoulder elevation. J Electromyogr Kinesiol 2007;17(2):153-159.

47. Panka GF, Oliveira MM, França DC, Parreira VF, Britto RR,
Velloso M. Ventilatory and muscular assessment in healthy subjects during an activity of daily living with unsupported arm elevation. Rev Bras Fisioter 2010;14(4):337-344. Article in Portuguese.

48. Villaça DS, Lerario MC, Dal Corso S, Nápolis L, de Albuquerque AL, Lazaretti-Castro M, et al. Clinical value of anthropometric estimates of leg lean volume in nutritionally depleted and non-depleted patients with chronic obstructive pulmonary disease. Br J Nutrition 2008;100(2):380-386. 